Check for updates

Cite this: RSC Adv., 2017, 7, 47425

Received 2nd September 2017 Accepted 2nd October 2017

DOI: 10.1039/c7ra09781f

rsc.li/rsc-advances

\section{DNA-based nanoscale walking devices and their applications}

\begin{abstract}
Yikang Xing, $\uparrow$ Bing Liu, $\uparrow$ Jie Chao* and Lianhui Wang (DD*
The rapidly growing field of nanodevices is attracting more and more attention on account of their ingenious design and broad application. Taking advantage of the sequence specificity and excellent programmability of DNA molecules, numerous DNA devices with multiple functions have been designed and fabricated such as tweezers, gears, cranes and so on. DNA walking devices are the most sophisticated ones either in design or fabrication. They exhibit a powerful ability to actuate walkers walking on their tracks. Herein we review DNA walking devices based on walking functions including unipedal, bipedal, multipedal, and other novel walking devices, as well as their applications.
\end{abstract}

\section{Introduction}

The field of nanodevices is one of the more challenging frontiers at present. It is important for us to understand the law of energy conversion at the nanoscale, as well as the interaction and regulation mechanism between biological molecules. ${ }^{1-3}$ Many scientists have paid extensive attention to this field in recent years. ${ }^{4-11}$ As DNA owns the distinguished principle of Watson-Crick base pairing and special physical character, it has been nominated as one of the most versatile and robust building materials, not only to construct controllable nanoarchitectures in nanoscale resolution with excellent sequence programmability and structural rigidity, but also to provide memory components in dynamic structures with high fidelity.

Institute of Advanced Materials (IAM), Jiangsu National Syngerstic Innovation Center for Advanced Materials (SICAM), Nanjing University of Posts \& Telecommunications, Nanjing 210023, China.E-mail: iamjchao@njupt.edu.cn; iamlhwang@njupt.edu.cn $\dagger$ These authors contributed equally to this work.
DNA origami has been proven as one of the most attractive breakthroughs offering a compelling approach leading toward the precise design of nanostructures with predestinate addressability at sub-10 $\mathrm{nm}$ resolution. Since then, numerous DNA origami nanostructures with different shapes have been constructed including rectangles, stars, smiley faces, maps, dolphins and three-dimensional (3D) structures such as honeycomb lattices, nanotubes, boxes and nanoflasks. ${ }^{12-19}$ Inspired by kinesin movement along a microtubule to perform intracellular transport in biological systems, ${ }^{\mathbf{2 0}-23}$ researchers have extended the area of DNA nanotechnology from structure to function, that is, converting static DNA nanostructures to dynamic, functional DNA nanodevices such as tweezers, gears, cranes and so on. ${ }^{21,24-26}$ DNA walking devices are the most sophisticated ones either in design or fabrication. ${ }^{27-33}$ They have exhibited a powerful ability to actuate walkers walking on their tracks from starting point to destination. ${ }^{34-39}$

Generally, the concept of DNA walking devices refers to a walking body such as a DNA duplex, nanoparticle or nanorod,

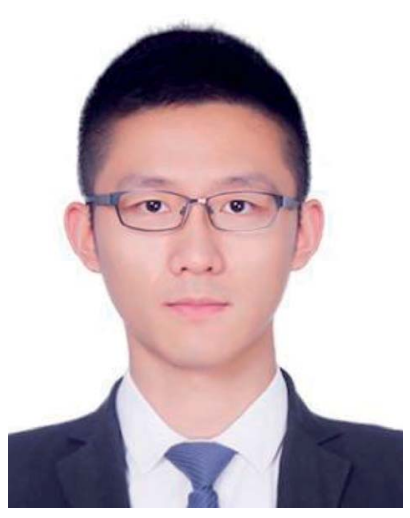

Yikang Xing is currently a postgraduate student under the supervision of Prof. Lianhui Wang at Nanjing University of Posts \& Telecommunications. His current research focuses on constructing DNA nanostructures with some applications.

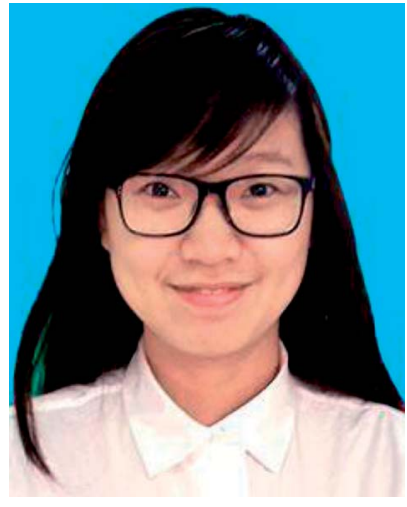

Bing Liu received her Ph.D. degree in Biology from Sichuan University in 2017. She currently works at Nanjing University of Traditional Chinese Medicine as a lecturer. Her research mainly involves DNA nanotechnology and the structure of biological macromolecules. 
and a track in multiple dimensions. For synthetic DNA walking devices, the walking process is usually enabled by the combination of strand hybridization, ${ }^{\mathbf{4 0}-43}$ enzymatic reaction $^{44,45}$ and environmental stimuli. ${ }^{46-53}$ Although DNA walking devices remain a mystery with respect to their low fidelity and slow rates, they still have great potential for various applications, such as sensors ${ }^{54-56}$ and switchable carriers. ${ }^{57-61}$ Generally, the ample evidence presented enables us to reasonably conclude that the enhancement of complexity regarding scale and speed is an area to be addressed. It can be believed that DNA walking devices will play a significant role in delivering targeted drugs into a patient's body to cure corresponding diseases in future.

On the basis of summarizing the previous work and combining the latest developmental achievements, herein we review the construction of nanostructures including unipedal, bipedal, multipedal, and other novel walking devices, and the applications of DNA nanomachines are also summarized.

\section{Unipedal walking devices}

Unipedal walking devices refer to one "foot" travel on a track from a morphological perspective. Single-foot DNA walking devices are probably the simplest formation because a single DNA strand plays the leading role. Wickham et $a .^{62}$ used a single strand of DNA as a walking device to move autonomously along the full length of a track (Fig. 1a). Single-stranded stators on a DNA origami tile constitute a $100 \mathrm{~nm}$-long DNA track. With the help of a nicking enzyme, the unipedal walking device took up to 16 consecutive steps by branch migration. Later, Endo's group ${ }^{63}$ developed a DNA nanodevice with lightfuelled mechanical movements (Fig. 1c). These pyrenemodified walking strands migrated from one cleaved stator to the next on a similar 2D DNA origami tile. It is good to be reminded that these two stepwise walking systems were directly observed by high-speed AFM in real-time, which tended to facilitate the development of systems that could be programmed and routed by instructions encoded in the nucleotide sequences of the track and walking strands.

Generally, these walking nanodevices are mostly fueled by enzymatic reactions or powered by light. The external addition of counterpart strands is also an important class of reaction utilized in dynamic DNA nanotechnology. Simmel and his coworkers ${ }^{64}$ utilized walking devices based on origami to investigate the effect of colocalization on the performance of DNA strand displacement (DSD) reactions (Fig. 1b). Devoted to immobilizing a two-stage DSD reaction cascade, the system was composed of "sender" and "receiver" gates in a DNA origami platform, in which the additional DNA input strand displaced a signal strand from the sender gate and then transferred to the receiver gate.

In fact, considerable research efforts on single-foot walking devices have been devoted to the development from a 2D track to $3 \mathrm{D}$ track. Originally, Jung et al. ${ }^{65}$ reported a stochastic DNA walking device that traversed a microparticle surface in a creative way (Fig. 1d). The DNA walking device utilized hybridization energy to drive walking on a 3D track, which was the DNAcoated microparticle surface. It showed that the walking traversal could cover more than 30 continuous steps entirely due to autonomous decisions made by the walking device. This system shines a light on the future development of DNA walking devices that travel on the nanoparticle, and has been confirmed by other studies. Recently, Qu and his coworkers ${ }^{66}$ constructed a single-foot DNA walking device consisting of a 21-base sequence with five consecutive thymines (oligo-T) (Fig. 1e). The 3D track refers to $15 \mathrm{~nm}$-sized gold nanoparticles (AuNPs) decorated with thiol-tagged oligonucleotides. Moreover, the movement avoided randomly hydrolyzing RNA sequences owing to exonuclease III, and the system has great potential for analytical and diagnostic applications.

\section{Bipedal walking devices}

Compared to unipedal walking devices, it is better to link bipedal walking devices to pincers because two "feet" drive

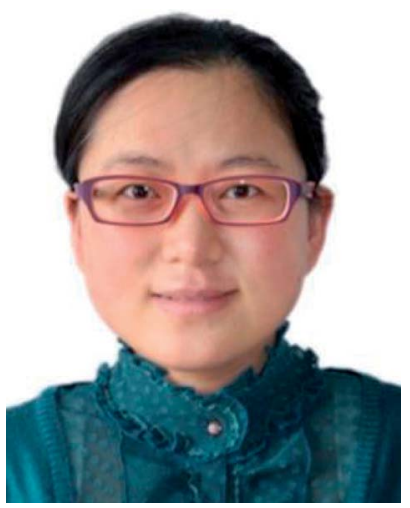

Jie Chao received her $P h D$ from Nanjing University in 2008. In 2006-2007, she was a visiting student in Prof. Seeman's laboratory at New York University. After her postdoctoral research at Nanjing University, she joined the Shanghai Institute of Applied Physics (SINAP) in 2011 as an associate professor. In 2014, she moved to Nanjing University of Post \& Telecommunications as a professor. Her research interests focus on DNA nanostructures and their applications.

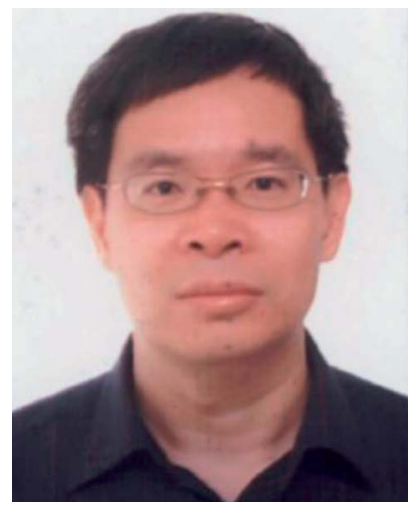

Lianhui Wang graduated from Fujian Normal University with a MS degree in 1993. Then he received his $P h D$ degree from Zhejiang University in 1998. After working in the National University of Singapore for seven years, he joined Fudan University as a professor in 2005. In 2011, he moved to Nanjing University of Post \& Telecommunications as a chair professor. His research interests include nanobiology, chemical biology, bioelectronics, biosensors and so on. He has published over 100 papers in international, peer-reviewed journals, the citations of which exceed 2500 giving him an h-index of 27. 
(a)
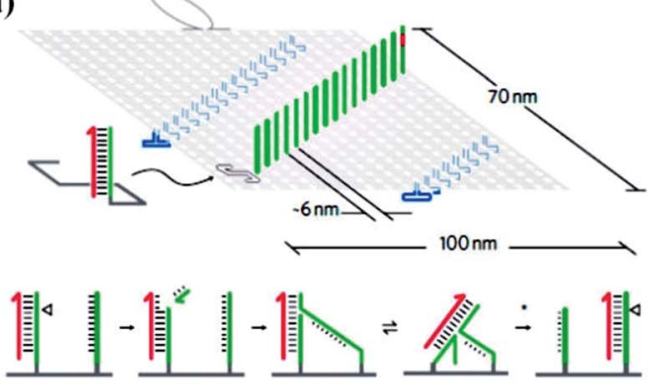

(d)

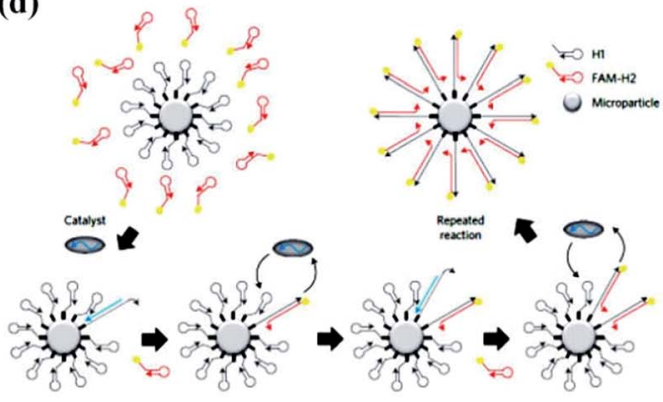

(b)
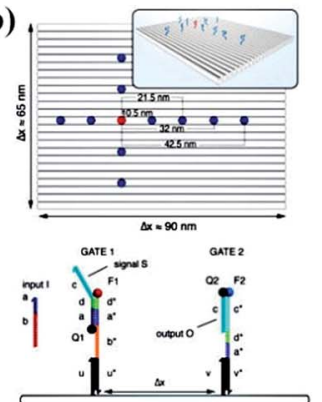

(e)
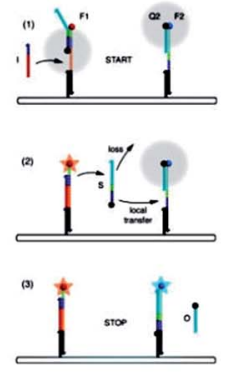

(c)
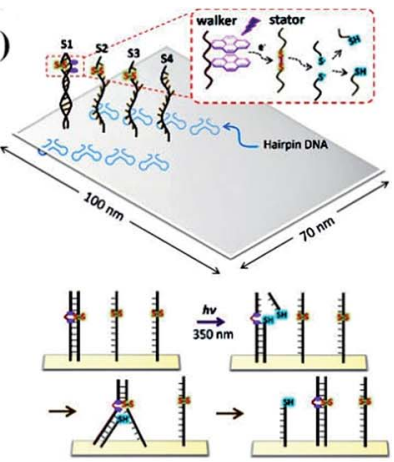
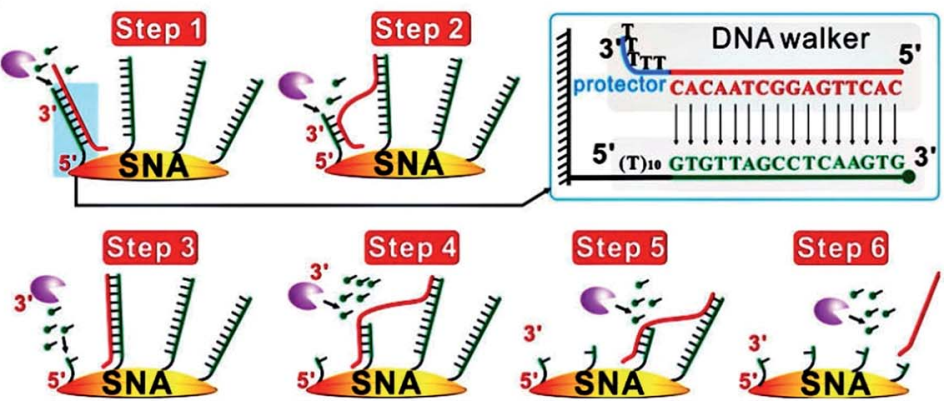

Fig. 1 Unipedal DNA walking devices. (a) The layout of the DNA origami tile and walker mechanism. ${ }^{62}$ A nicking enzyme cuts the motor-bound stator revealing a toehold at the $3^{\prime}$ end of the motor (magenta) that facilitates the transfer of the motor to the adjacent intact stator by branch migration. (b) An illustration of a rectangular single-layered DNA origami platform and the immobilized DNA strand displacement cascade. ${ }^{64}$ (c) An illustration of a rectangular DNA tile and light-driven walking system. ${ }^{63}$ (d) A schematic of a catalytic hairpin assembly reaction on a microparticle surface shows how fluorescent FAM-H2 (red hairpins) are catalytically hybridized to surface-immobilized $\mathrm{H} 1$ (grey hairpins). ${ }^{65}$ (e) Schematics for Exo III-powered stochastic DNA walkers that move on SNA surfaces. ${ }^{66}$ Adapted with permission from ref. 62 and 65, Copyright 2011 and 2016 Nature Publishing Group, ref. 63 and 64, Copyright 2015 and 2014 American Chemical Society, and ref. 66, Copyright 2017 WileyVCH Verlag GmbH \& Co. KGaA Weinheim.

walking sideways. For bipedal walking devices, three substantial problems must be considered. Firstly, we have to take measures to work out the challenge that some random thermal motions always hinder bipedal walking devices from moving in a synchronized way. Omabegho et al. ${ }^{67}$ reported a bipedal DNA Brownian motor with coordinated legs to cyclically catalyze the hybridization of metastable DNA fuel strands (Fig. 2a). This process led to a chemically ratcheted movement along a track with directional double-crossover (DX). The successive transition and full walking cycle helped to uncover principles behind the design of unidirectional devices that could function without intervention.

Secondly, it is known that gel electrophoresis, fluorescence microscopy, atomic force microscopy (AFM), and transmission electron microscopy (TEM) techniques are widely applied in studying dynamic movement, but it is difficult to measure timedependent conformational changes and protect samples from damage. To address this problem, Nir's group ${ }^{68}$ presented a detailed single-molecule fluorescence study based on an autonomous bipedal DNA walking device (Fig. 2b). Their work demonstrated that single-molecule fluorescence constituted an excellent tool for chaperoning the development of DNA-based technology, which was used appropriately and efficiently in another paper reported by them three years later. ${ }^{69}$ The singlemolecule fluorescence characterization showed the successful operation of a dynamic DNA walking device, striding back and forth between two origami tiles (Fig. 2c). This bipedal DNA walking device system was programmed by sequential interaction with "fuel" and "antifuel" DNA strands that resulted in movement from one origami tile to another and back again. As the track consisted of two different DNA origami tiles, this study has contributed to disclosing secrets behind the design of DNA walking devices that could stride over micrometer distances.

The third challenge is the speed of the walking devices. In 2012, Wang et $a .^{70}$ elaborated a strategy to accelerate the DNA walking process on a three foothold molecular track through the use of a DNA catalyst (Fig. 2d). The advantage of using strand-displacement-based catalysts over enzymes is that the former generally have fewer sequence constraints and are less likely to be influenced by environmental conditions, such as $\mathrm{pH}$, temperature, and salt concentrations. The locomotion is about one order of magnitude faster than previous hybridization-based bipedal walking devices.

In addition to DNA hybridization, light powering and enzyme triggering, DNA walking devices can also be activated by $\mathrm{H}^{+} / \mathrm{OH}^{-}$or $\mathrm{Hg}^{2+}$ ions/cysteine which was reported by the group of Willner (Fig. 2e). ${ }^{71}$ Their principle for operating a bipedal walking device was aimed at constructing four nucleic acid footholds on a DNA template and building the signal-triggered motility of a "walker" nucleic acid tethered to two of the footholds in each state of the machine. Importantly, it was a reversible bipedal DNA walking device because one sequence 
(a)
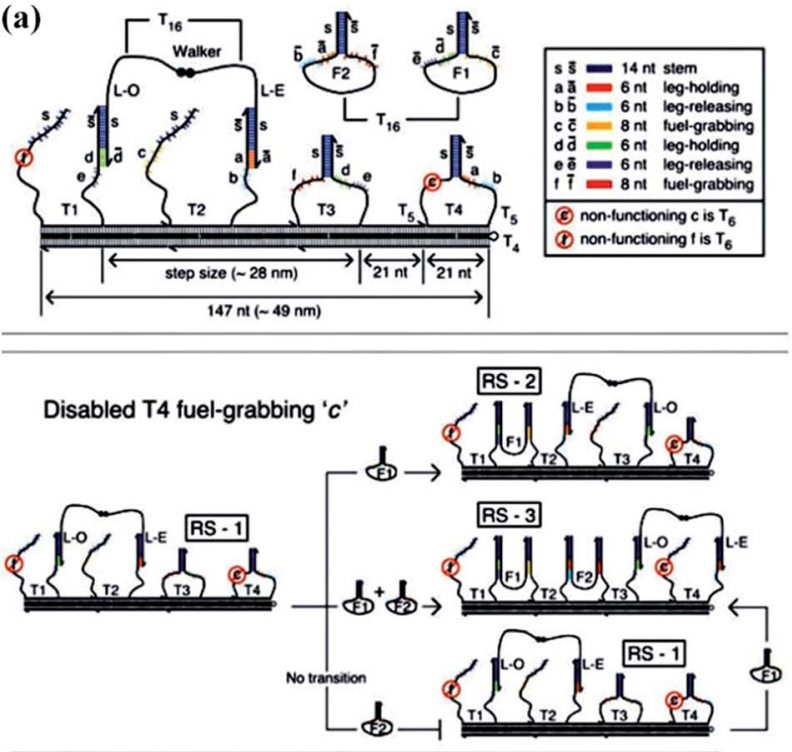

Restored T4 fuel-grabbing ' $c$ '

(2)

(d)
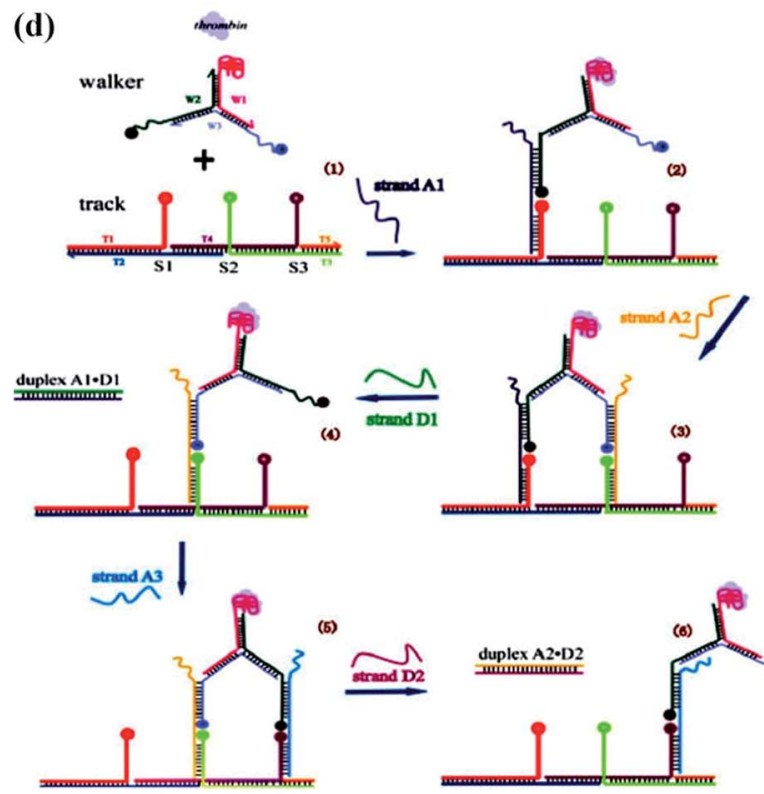

(b)

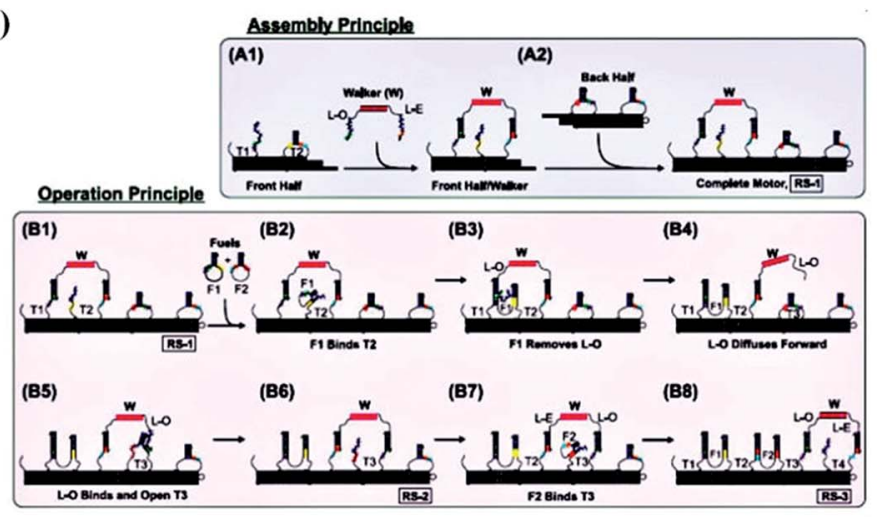

(c)

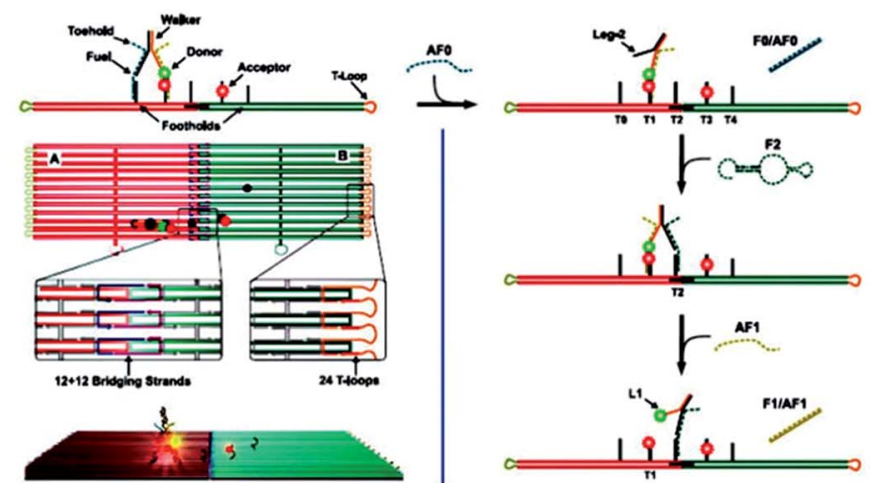

(e)

Fig. 2 Bipedal DNA walking devices. (a) An illustration of the DX track structure with the walker on it. ${ }^{67}$ (b) A schematic representation of the motor's assembly and principle of operation..$^{68}$ (c) The design of the origami track and the bipedal motor, and the motor operation principle. ${ }^{69}$ (d) A strategy to speed up bipedal DNA walking devices through the use of DNA catalysts..$^{70}$ (e) A bipedal DNA walker powered by $\mathrm{H}^{+} / \mathrm{OH}^{-}$or $\mathrm{Hg}^{2+}$ ions/cysteine from its environment. ${ }^{71}$ Adapted with permission from ref. 67, Copyright 2009 American Association for the Advancement of Science, ref. 69, Copyright 2015 Wiley-VCH Verlag GmbH \& Co. KGaA Weinheim, ref. 68 and 70, Copyright 2012 American Chemical Society, and ref. 71, Copyright 2011 American Chemical Society.

of the complementary nucleic acids responded to $\mathrm{Hg}^{2+}$ ions, which detached from the former foothold and attached to the next, and the other responded to $\mathrm{H}^{+}$ions, which led to the formation of an i-motif structure. Similarly, the backward movement was activated by $\mathrm{OH}^{-}$ions and cysteine that destroys the i-motif or thymine- $\mathrm{Hg}^{2+}$-thymine complexes.

\section{Multipedal walking devices}

In dynamic DNA nanotechnology, three-feet DNA walking devices have been constructed infrequently. However, multipedal walking devices comprising an anisotropic nanoparticle as the body and discrete DNA or RNA strands as the feet have 
been widely studied. Consequently, this suggests that multipedal nanodevices with longer distance and higher fidelity and rates must predominate in the future.

In 2010, Seeman's group ${ }^{72}$ designed a proximity-based programmable DNA nanoscale assembly line to satisfy a DNA walking device assembling cargos as it travelled (Fig. 3a). The core part of the system was the walker structure, containing three hands and four feet and moving along the track to collect and transfer different cargos (AuNPs). Coincidentally, another three-leg DNA walking device was built by Yan and his colleagues at the same time. ${ }^{73}$ The molecular spider was made up of one streptavidin molecule as an inert body and three 8-17 bp DNA enzymes as catalytic legs that cleaved oligonucleotide substrates at single ribose sites into shorter strands (Fig. 3c). However, the spider DNA walking device was not fast, efficient, or powerful enough due to the core principle of the catalytic reaction of DNAzymes. In order to speed up the walking process, Salaita's group ${ }^{74}$ successfully designed relatively fast DNA walking devices, DNA-modified particles (Fig. 3b). The maximum speed was three orders of magnitude greater than the maximum for conventional DNA motors. RNase $\mathrm{H}$ selectively hydrolysed the hybridized RNA modified on a surface to hybridize the DNA-coated spherical particles, which resulted in a rolling movement rather than walking. Also, the nanodevice could travel in a self-avoiding fashion and anisotropic particles could travel linearly without a track or external force.

Furthermore, in answer to the formidable challenge of precise transport, Liu et al. ${ }^{75}$ designed a gold nanorod (AuNR) that can perform stepwise walking directionally and progressively on DNA origami (Fig. 3d). In the active plasmonic system, two AuNRs assembled perpendicularly to one another were placed on two opposite surfaces of a $2 \mathrm{D}$ rectangular DNA origami platform. The walking process triggered a series of conformational changes, thus giving rise to immediate spectral response changes that can be read out optically. Therefore, its own walking directions and consecutive steps could be optically reported in situ. Moreover, stepwise walking of the walking device on a 3D origami platform, triangular prism origami, was examined.

\section{Other novel walking devices}

To date, researchers have paid more attention to individual walking device behavior. However, few attempts have been made to implement multiple artificial walking devices which have the advantage of walking collectively on the same track. In another report from Liu's group, ${ }^{76}$ they demonstrated a plasmonic walking device couple system involving two AuNR walking devices which could perform simultaneous walking along the same DNA origami track (Fig. 4a). It was crucial that the number of walking devices was related to the optical response of the system which probably made a contribution to developing advanced artificial nanomachinery with multiple walking devices in concert.

Most frequently, the autonomous movements of DNA walking devices depend on the cleavage of endonucleases or (a)<smiles>CC1(C)CCCC12CCCC2</smiles>
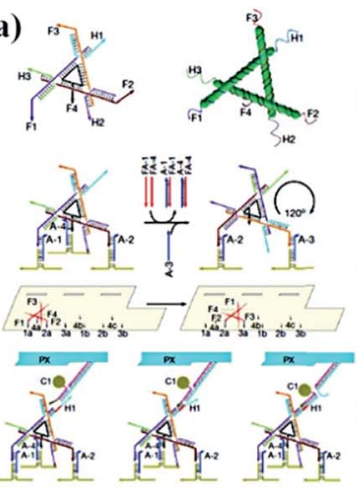

(c)
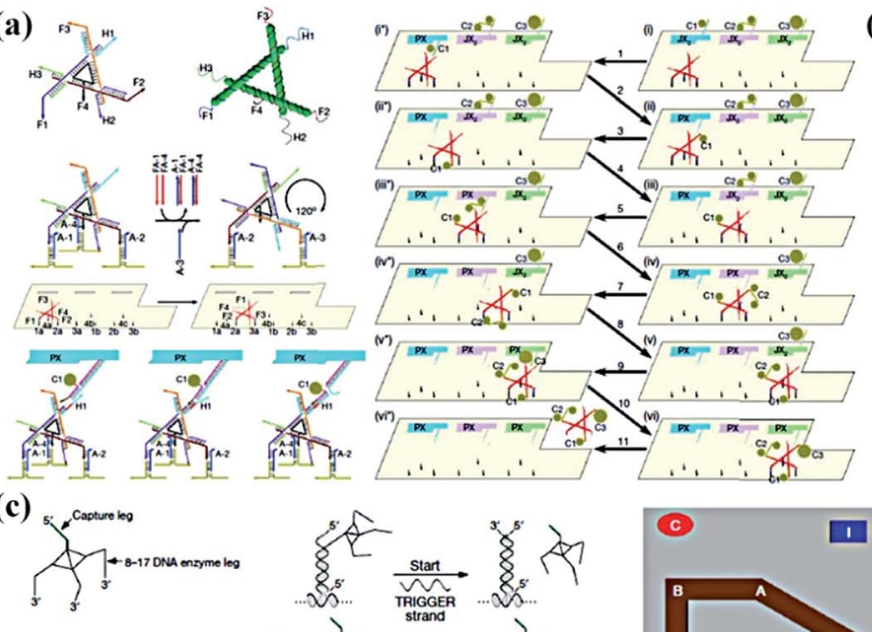

(b)
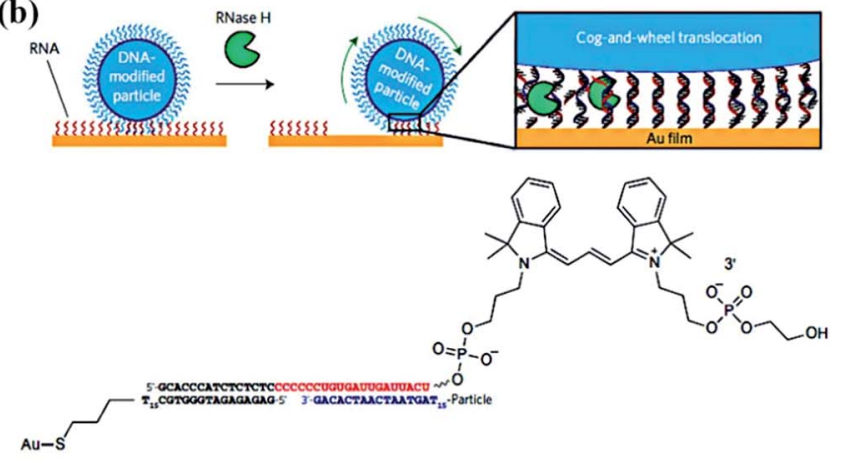

(d)
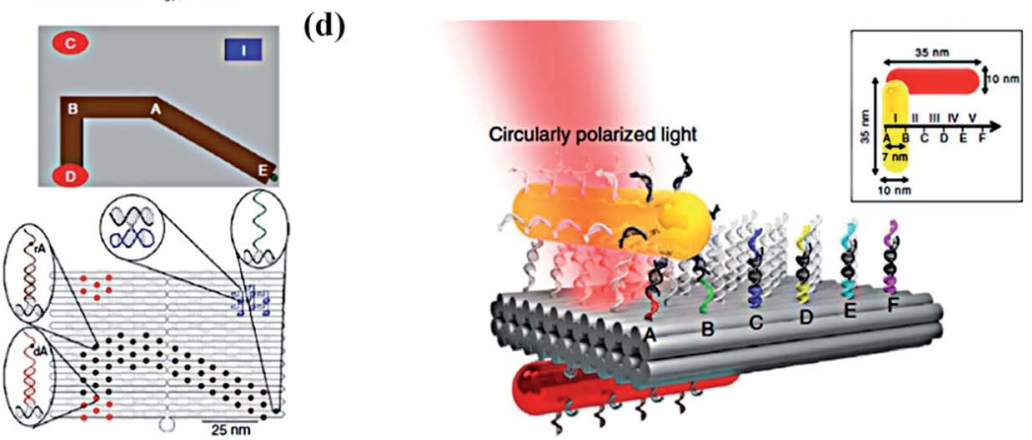

Fig. 3 Multipedal DNA walking devices. (a) Details of the three-feet walking device, the molecular assembly line and its operation. ${ }^{72}$ (b) The approach used to generate RNA-fuelled, enzyme-catalysed autonomous DNA motors. ${ }^{74}$ (c) A deoxyribozyme-based molecular walker called a molecular spider and the origami prescriptive landscape..$^{73}$ (d) A schematic of the plasmonic multipeda walking device. ${ }^{75}$ Adapted with permission from ref. 72 and 73, Copyright 2010 Nature Publishing Group, and ref. 74 and 75, Copyright 2016 and 2015 Nature Publishing Group. 

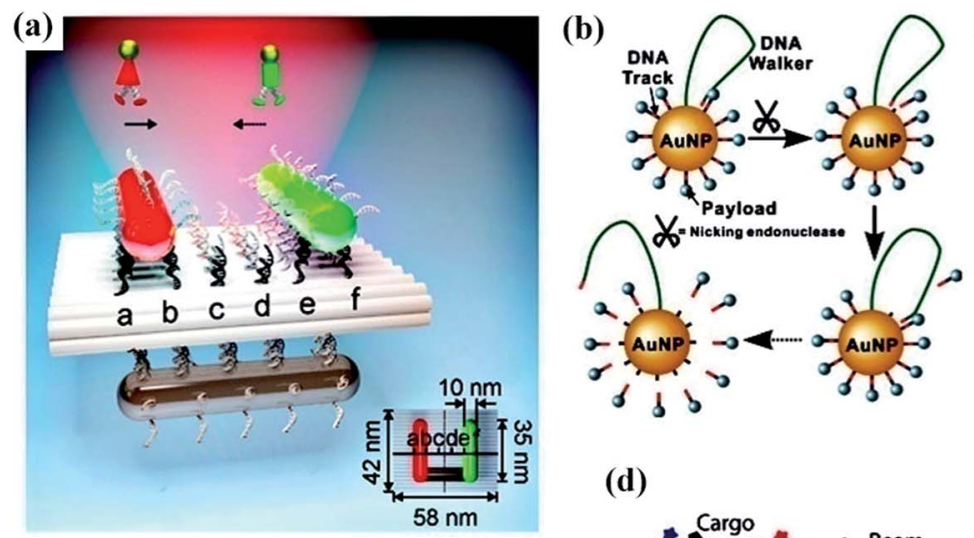

(c)

(d)
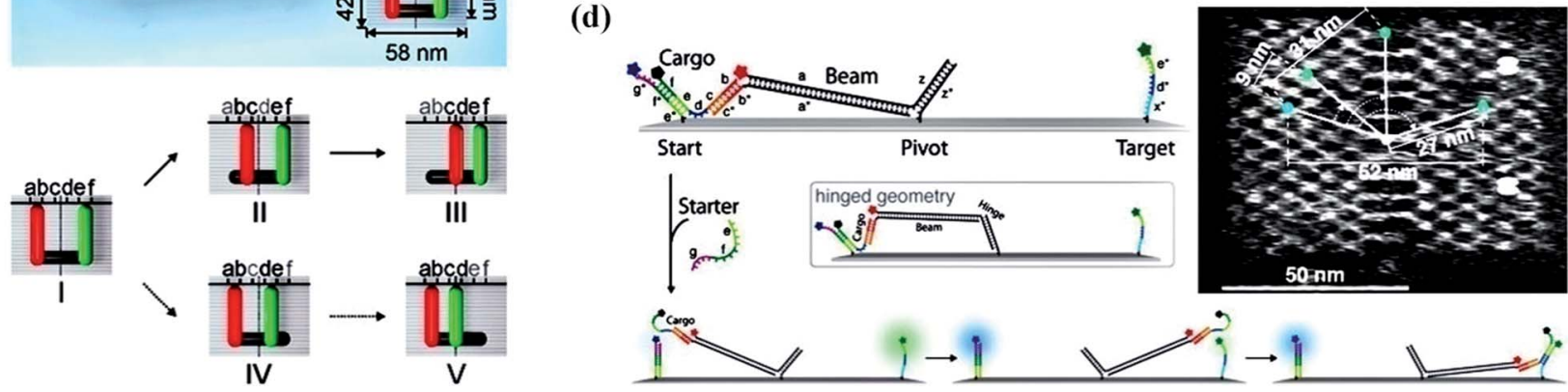

Fig. 4 Several novel walking devices. (a) A schematic of the plasmonic walker couple and stepwise walking of the individual walkers. ${ }^{76}$ (b) A schematic illustrating the principle of the 3D DNA nanomachine constructed by co-conjugating DNA walker and DNA track (substrate) components on a single AuNP..$^{77}$ (c) An illustration of the control of the conformation of a polymer on predesigned ssDNA tracks of staple strands extending from rectangular DNA origami. ${ }^{79}$ (d) A schematic side view of a DNA origami platform with a rigid tether fixed in the center and the mechanism of cargo transport and fluorescence labeling. ${ }^{78}$ Adapted with permission from ref. 76 and 78 , Copyright 2015 American Chemical Society, and ref. 77 and 79, Copyright 2016 American Chemical Society.

deoxyribozymes, or photoirradiation, resulting in the relatively slow kinetics and limited steps of movement. Li and coworkers $^{77}$ creatively built an enzyme-powered 3D DNA nanomachine to execute walking, resolving the task of releasing payloads (Fig. 4b). A DNA-functionalized gold nanoparticle (DNA-AuNP) served as the 3D track, while the long DNA strand which was inserted into the AuNP acted as the walking device. Powered by a nicking endonuclease, the DNA walking device cleaved multiple specific substrates on the track and plentiful payload fell off.

As pointed out in the previous reports, much effort on the movement of DNA walking devices had been emphasized particularly on utilizing a flexible and hinged tether with the help of environmental stimuli in order to achieve fast and efficient transport of molecular cargo along tracks. On the contrary, Simmel and his co-workers ${ }^{78}$ developed a rigid tether that can rotate to mediate cargo transfer from the start to a target site on the DNA origami structure, which presented very fast, robust and more efficient motion over long distances (Fig. 4d). Gothelf et al. ${ }^{79}$ redefined DNA walking devices because they described the development of a nanomechanical device that allowed switching of the position of a single-molecule conjugated polymer (Fig. 4c). The DNA polymer conjugate, functionalized with short single-stranded (ss) DNA strands extending from the backbone, could be aligned on DNA origami in three well-defined geometries (straight line, left-turned, and right-turned patterns).
Therefore, it shows that these novel walking devices have been developed on the strength of increasing the number of walking devices on the same track, constructing 3D nanomachine systems, and replacing the walking process with rolling, switching and pivoting. Although the theories of these nanodevices still focus on hybridization, enzymatic reaction and environmental stimuli, these systems always differ from the traditional systems.

\section{Applications of DNA walking devices}

DNA nanomachines that walk by converting chemical entropy into controlled motion could be of good use in applications such as biosensing, ${ }^{80-82}$ molecular computing ${ }^{83-85}$ and drug delivery. ${ }^{86-88}$ It is nucleic acids that are adept in molecular computation, especially constructing numerous molecular logic gates which have been combined to form various molecular circuits. $^{89-92}$ In addition, some specific 3D nanostructures, including DNA nanotubes, DNA tetrahedra and DNA origami structures, reveal the promising features to be the use as universal nanocarriers for cargo or drug delivery.

Recently, Ding and his coworkers ${ }^{93}$ designed a targetswitched DNA nanotweezer for AND logic gate operation and sensitive enzyme-free biosensing of microRNAs (Fig. 5a). An arched structure as the set strand for the target inputs and two split G-rich DNAs at the termini of the two arms for the signal output play significant roles in the building of the nanotweezer. 
When a catalytic hairpin assembles, numerous open nanotweezers switch to a closed state owing to these binary target inputs. This logical process directly results in the formation of a proximity-dependent DNAzyme in the presence of hemin to produce a highly sensitive biosensing system.

In 2013, Willner's group ${ }^{94}$ demonstrated the powerful biosensing function of DNA walking devices (Fig. 5b). They described a DNA walking device assembled on nucleic acid scaffolds and triggered by fuel/antifuel strands. The walking device successfully switched formation or dissociation of the
hemin/G-quadruplex DNAzyme on the DNA scaffolds, which enabled the chemiluminescence, chemiluminescence resonance energy transfer (CRET), or the electrochemical or photoelectrochemical transduction of the walking processes.

With regards to drug delivery, Gothelf and Kjems's group ${ }^{95}$ spared no effort to make a DNA origami box with a controllable lid (Fig. 5c). The lid of this DNA box had a dual lock-key system composed of DNA duplexes with sticky-end extensions as the "toehold" which will be displaced by introducing "key" oligonucleotides and then the lid will be opened. With the help of

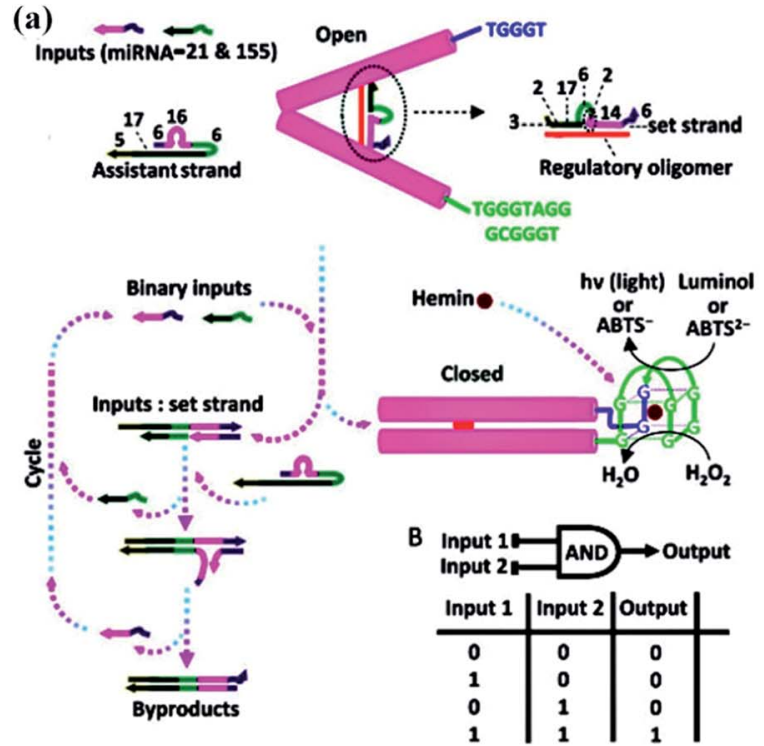

(d)

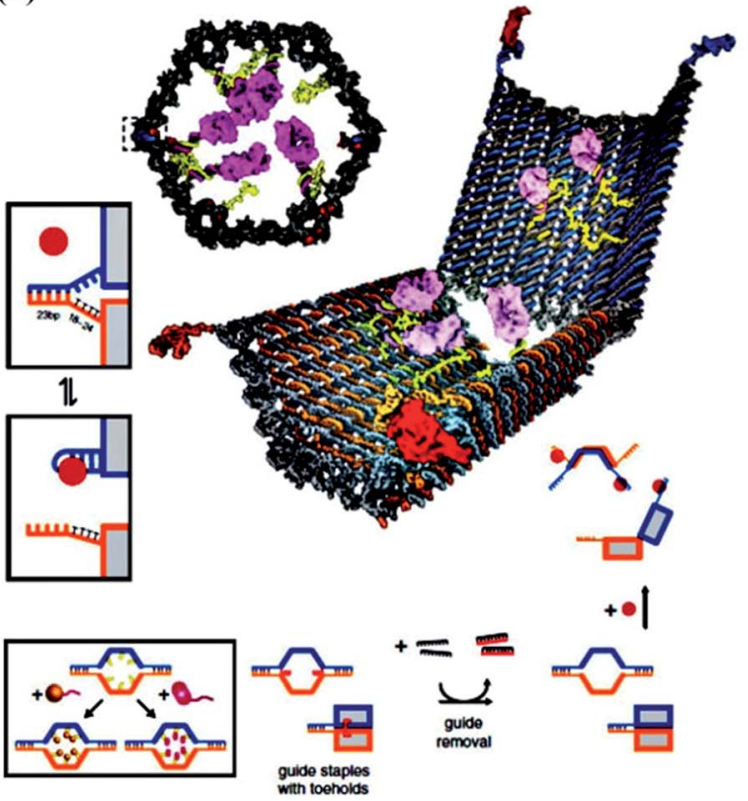

(b)

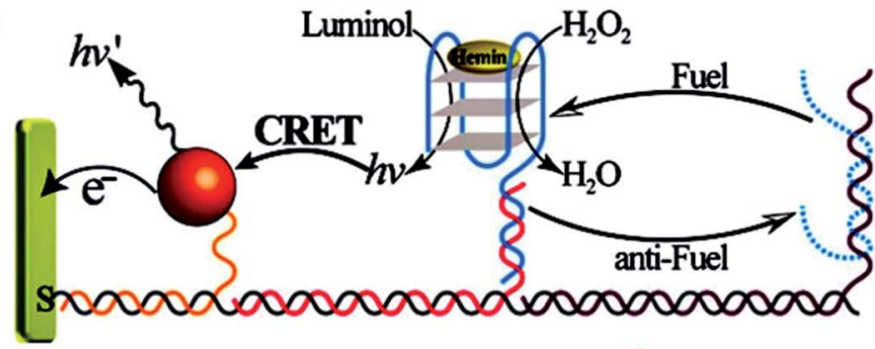

(c)

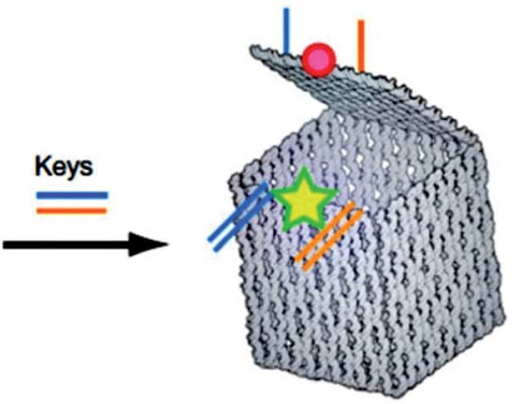

(e)

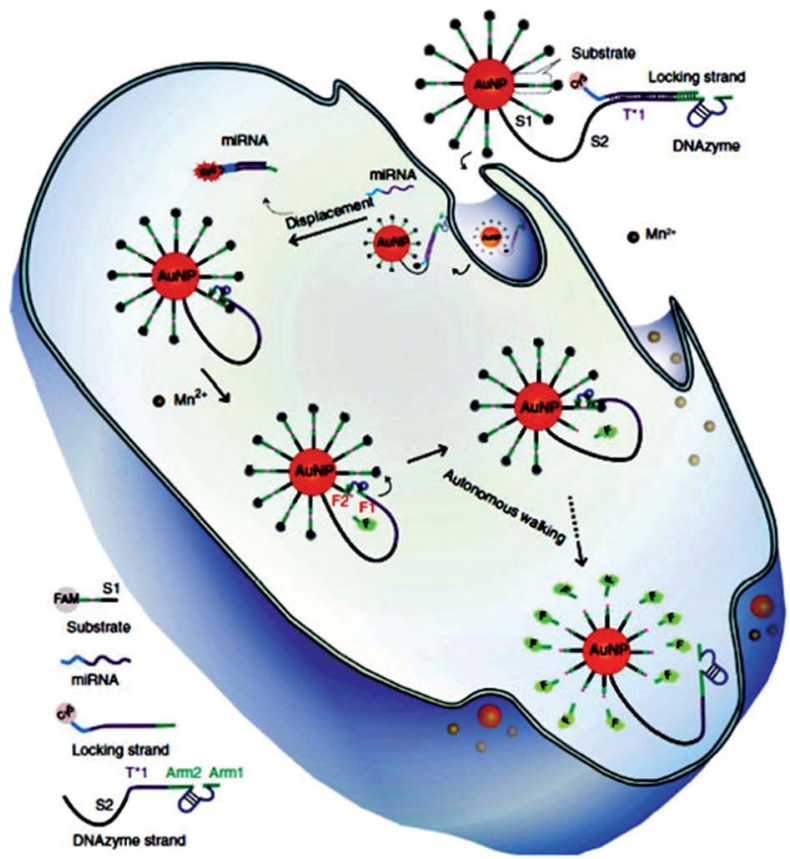

Fig. 5 Applications of DNA walking devices. (a) A target-switched DNA nanotweezer for AND logic gate operation and sensitive enzyme-free biosensing of microRNAs. ${ }^{93}$ (b) The switching photonic and electrochemical functions of a DNAzyme by DNA walking devices. ${ }^{94}$ (c) A nanoscale DNA box with a controllable lid used to combine a diagnostic sensor of complex signals..$^{95}$ (d) A logic-gated nanorobot for targeted transport of molecular payloads. ${ }^{96}$ (e) Intracellular operation of a DNAzyme motor initiated by a specific miRNA in living cells. ${ }^{97}$ Adapted with permission from ref. 93 and 94, Copyright 2016 and 2013 American Chemical Society, ref. 95 and 97, Copyright 2009 and 2017 Nature Publishing Group, and ref. 96. Copyright 2012 American Association for the Advancement of Science. 
efficient fluorescence resonance energy transfer (FRET), researchers effectively monitored the operation of closing and opening. This profound work in building a DNA box has the potential to combine a diagnostic sensor of complex signals with the controlled release or access of a payload. Douglas' group $^{96}$ took a giant step forward to realize the biological application of a DNA origami nanorobot in the form of a hexagonal barrel with dimensions of $35 \mathrm{~nm} \times 35 \mathrm{~nm} \times 45 \mathrm{~nm}$ (Fig. 5d). The barrel consisted of two domains that were covalently attached in the rear by single-stranded scaffold hinges, and could be noncovalently fastened in the front by staples modified with DNA aptamer-based locks. The aptamer-encoded locks function as an AND logic gate responding to molecular inputs (keys) which are expressed by cells. Plenty of practical experiments have been carried out, demonstrating that the robot can inspire new designs with different selectivities and biologically active payloads for cell-targeting tasks.

It should be pointed out that much work has focused on constructing various synthetic DNA motors to mimic the functions of protein motors. All of this effort aims ultimately at the operation of synthetic DNA motors in living cells. To our delight, Peng and his coworkers ${ }^{97}$ invented a DNAzyme motor that operated in living cells with a response to a specific intracellular target (Fig. 5e). Their DNA walking device referred to a $20 \mathrm{~nm}$ AuNP functionalized with hundreds of substrate strands, and dozens of DNAzyme molecules were silenced by a locking strand. After entering a living cell, the target miRNA was hybridized to the locking strand and released the locking strand from the DNAzyme through a strand displacement reaction, which drove the DNAzyme motor to traverse along the AuNP surface. The process of this stepwise walking inside the cell was monitored in real-time through the fluorescence of FAM.

\section{Summary and perspectives}

From the discussed research above, the complexity of DNA walking devices has been enhanced from one "foot" travel to multipedal movement, and even to complex assemblies involving tweezers, ${ }^{\mathbf{9 8 - 1 0 3}}$ cranes, ${ }^{\mathbf{1 0 4 , 1 0 5}}$ catenanes, ${ }^{\mathbf{1 0 6}}$ rotaxanes, ${ }^{107,108}$ metronomes, ${ }^{109}$ gears ${ }^{\mathbf{1 1 0}}$ and spiders. The track has also been promoted from individual DNA strands to 2D or 3D forms. ${ }^{111-116}$ Despite the fact that these outstanding DNA nanomachines have been proven to possess exquisite programmability and addressability with the help of FRET, ${ }^{117,118}$ electrophoretic experiments, or fast AFM measurements on surfaces, there still remain challenges for future development, such as the scale and speed. The good news is that researchers have tried their best to design and manipulate more and faster walking devices in the form of rotating or rolling and larger nanostructures including DNA nanotubes, DNA tetrahedra and DNA origami boxes. Suitable applications for DNA walking devices have been a matter of continuous exploration, including drug delivery, mediating organic synthesis, ${ }^{119}$ programmed control of RNA expression and computation.

It is difficult to predict the practical application of these smart walking devices, but just as Feringa, one of the 2016
Nobel Prize winners for chemistry, said "People were saying, why do we need a flying machine? Now we have a Boeing 747 and an Airbus. That's a little bit how I feel. The opportunities are great." It is deserved to imagine that walking devices could be used as tiny robots in people's bodies to deliver drugs or detect cancerous cells, or as smart materials that could adapt or change depending on external signals. Anyway, it's time to pay more attention to develop DNA walking devices because they are coming.

\section{Conflicts of interest}

There are no conflicts to declare.

\section{Acknowledgements}

This work was financially supported by the Ministry of Science and Technology of China (2017YFA0205302), Sci-tech Support Plan of Jiangsu Province (BE2014719), Program for Changjiang Scholars and Innovative Research Team in University (IRT_15R37), Natural Science Foundation of Jiangsu Province (BK20151504), Priority Academic Program Development of Jiangsu Higher Education Institutions (PAPD, YX03001), Megaprojects of Science and Technology Research (AWS13C007) and NUPTSF (Grant no. 214175).

\section{References}

1 R. D. Astumian, Science, 1997, 276, 917-922.

2 C. Bustamante, D. Keller and G. Oster, Acc. Chem. Res., 2001, 34, 412-420.

3 E. R. Kay, D. A. Leigh and F. Zerbetto, Angew. Chem., Int. Ed., 2007, 46, 72-191.

4 C. Mao, W. Sun, Z. Shen and N. C. Seeman, Nature, 1999, 397, 144-146.

5 S. K. Kufer, E. M. Puchner, H. Gumpp, T. Liedl and H. E. Gaub, Science, 2008, 319, 594-596.

6 W. B. Sherman and N. C. Seeman, Nano Lett., 2004, 4, 12031207.

7 J. S. Shin and N. A. Pierce, J. Am. Chem. Soc., 2004, 126, 10834.

8 Y. Tian, Y. He, Y. Chen, P. Yin and C. Mao, Angew. Chem., 2005, 117, 4429-4432.

9 R. A. Muscat, J. Bath and A. J. Turberfield, Small, 2012, 8, 3593-3597.

10 R. Hou, I. Y. Loh, H. Li and Z. Wang, Phys. Rev. Appl., 2017, 7, 024020.

11 J. Pan, T. G. Cha, F. Li, H. Chen, N. A. Bragg and J. H. Choi, Sci. Adv., 2017, 3, e1601600.

12 P. W. Rothemund, Nature, 2006, 440, 297-302.

13 L. Qian, Y. Wang, Z. Zhang, J. Zhao, D. Pan, Y. Zhang, Q. Liu, C. Fan, J. Hu and L. He, Chin. Sci. Bull., 2006, 51, 2973-2976.

14 E. S. Andersen, M. Dong, M. M. Nielsen, K. Jahn, A. Lindthomsen, W. Mamdouh, K. V. Gothelf, F. Besenbacher and J. Kjems, ACS Nano, 2008, 2, 1213. 
15 S. M. Douglas, H. Dietz, T. Liedl, B. Hogberg, F. Graf and W. M. Shih, Nature, 2009, 459, 414-418.

16 S. M. Douglas, J. J. Chou and W. M. Shih, Proc. Natl. Acad. Sci. U. S. A., 2007, 104, 6644-6648.

17 D. Han, S. Pal, J. Nangreave, Z. Deng, Y. Liu and H. Yan, Science, 2011, 332, 342-346.

18 K. E. Dunn, F. Dannenberg, T. E. Ouldridge, M. Kwiatkowska, A. J. Turberfield and J. Bath, Nature, 2015, 525, 82-86.

19 Y. He, T. Ye, M. Su, C. Zhang, A. E. Ribbe, W. Jiang and C. Mao, Nature, 2008, 452, 198-201.

20 M. Schliwa and G. Woehlke, Nature, 2003, 422, 759-765.

21 H. Liu and D. Liu, Chem. Commun., 2009, 2625-2636, DOI: 10.1039/b822719e.

22 R. D. Vale and R. A. Milligan, Science, 2000, 288, 88.

23 R. D. Vale, Cell, 2003, 112, 467-480.

24 M. J. Campolongo, S. J. Tan, J. Xu and D. Luo, Adv. Drug Delivery Rev., 2010, 62, 606-616.

25 Y. Lu and J. Liu, Curr. Opin. Biotechnol., 2006, 17, 580-588.

26 O. I. Wilner and I. Willner, Chem. Rev., 2012, 112, 25282556.

27 J. Cheng, S. Sreelatha, I. Y. Loh, M. Liu and Z. Wang, Methods, 2014, 67, 227-233.

28 J. Cheng, S. Sreelatha, R. Hou, A. Efremov, R. Liu, J. R. van der Maarel and Z. Wang, Phys. Rev. Lett., 2012, 109, 238104.

29 M. You, F. Huang, Z. Chen, R. W. Wang and W. Tan, ACS Nano, 2011, 6, 7935-7941.

30 S. J. Green, J. Bath and A. J. Turberfield, Phys. Rev. Lett., 2008, 101, 238101.

31 P. Yin, A. J. Turberfield and J. H. Reif, Lect Notes Comput. Sci., 2004, 41, 410-425.

32 J. Bath, S. J. Green, K. E. Allen and A. J. Turberfield, Small, 2009, 5, 1513-1516.

33 P. Yin, H. M. Choi, C. R. Calvert and N. A. Pierce, Nature, 2008, 451, 318-322.

34 S. F. Wickham, J. Bath, Y. Katsuda, M. Endo, K. Hidaka, H. Sugiyama and A. J. Turberfield, Nat. Nanotechnol., 2012, 7, 169-173.

35 R. A. Muscat, J. Bath and A. J. Turberfield, Nano Lett., 2011, 11, 982-987.

36 R. Pei, S. K. Taylor, D. Stefanovic, S. Rudchenko, T. E. Mitchell and M. N. Stojanovic, J. Am. Chem. Soc., 2006, 128, 12693.

37 F. C. Simmel, ChemPhysChem, 2009, 10, 2593-2597.

38 Z. Wang, Proc. Natl. Acad. Sci. U. S. A., 2007, 104, 1792117926.

39 P. Yin, H. Yan, X. G. Daniell, A. J. Turberfield and J. H. Reif, Angew. Chem., Int. Ed., 2004, 43, 4906-4911.

40 S. Venkataraman, R. M. Dirks, P. W. Rothemund, E. Winfree and N. A. Pierce, Nat. Nanotechnol., 2007, 2, 490-494.

41 R. M. Dirks and N. A. Pierce, Proc. Natl. Acad. Sci. U. S. A., 2004, 101, 15275-15278.

42 X. Olson, S. Kotani, B. Yurke, E. Graugnard and W. L. Hughes, J. Phys. Chem. B, 2017, 121, 2594-2602.

43 P. Gong, K. Wang, Y. Liu, K. Shepard and R. Levicky, J. Am. Chem. Soc., 2010, 132, 9663-9671.
44 J. Bath, S. J. Green and A. J. Turberfield, Angew. Chem., 2005, 117, 4432-4435.

45 J. H. Reif and S. Sahu, Theor. Comput. Sci., 2009, 410, 14281439.

46 C. Wang, J. Ren and X. Qu, Chem. Commun., 2011, 47, 14281430.

47 O. Mendoza, J. L. Mergny, J. P. Aime and J. Elezgaray, Nano Lett., 2016, 16, 624-628.

48 L. K. Bruetzel, T. Gerling, S. M. Sedlak, P. U. Walker, W. Zheng, H. Dietz and J. Lipfert, Nano Lett., 2016, 16, 4871-4879.

49 D. Liu and S. Balasubramanian, Angew. Chem., Int. Ed., 2003, 42, 5734-5736.

50 M. You, Y. Chen, X. Zhang, H. Liu, R. Wang, K. Wang, K. R. Williams and W. Tan, Angew. Chem., Int. Ed., 2012, 51, 2457-2460.

51 I. Y. Loh, J. Cheng, S. R. Tee, A. Efremov and Z. Wang, ACS Nano, 2014, 8, 10293.

52 J. Elbaz, B. Shlyahovsky and I. Willner, Chem. Commun., 2008, 13, 1569-1571.

53 M. Liu, R. Hou, J. Cheng, I. Y. Loh, S. Sreelatha, J. N. Tey, J. Wei and Z. Wang, ACS Nano, 2014, 8, 1792-1803.

54 C. Zhu, Y. Wen, D. Li, L. Wang, S. Song, C. Fan and I. Willner, Chemistry, 2009, 15, 11898-11903.

55 E. Johann, M. Michal, S. Bella and W. Itamar, Chemistry, 2009, 15, 3411-3418.

56 C. Zhu, Y. Wen, H. Peng, Y. Long, Y. He, Q. Huang, D. Li and C. Fan, Anal. Bioanal. Chem., 2011, 399, 3459-3464.

57 S. Ko, H. Liu, Y. Chen and C. Mao, Biomacromolecules, 2008, 9, 3039-3043.

58 A. S. Walsh, H. Yin, C. M. Erben, M. J. Wood and A. J. Turberfield, ACS Nano, 2011, 5, 5427-5432.

59 J. Li, H. Pei, B. Zhu, L. Liang, M. Wei, Y. He, N. Chen, D. Li, Q. Huang and C. Fan, ACS Nano, 2011, 5, 8783.

60 H. Lee, A. K. Lytton-Jean, Y. Chen, K. T. Love, A. I. Park, E. D. Karagiannis, A. Sehgal, W. Querbes, C. S. Zurenko, M. Jayaraman, C. G. Peng, K. Charisse, A. Borodovsky, M. Manoharan, J. S. Donahoe, J. Truelove, M. Nahrendorf, R. Langer and D. G. Anderson, Nat. Nanotechnol., 2012, 7, 389-393.

61 J. Fu and H. Yan, Nat. Biotechnol., 2012, 30, 407.

62 S. F. Wickham, M. Endo, Y. Katsuda, K. Hidaka, J. Bath, H. Sugiyama and A. J. Turberfield, Nat. Nanotechnol., 2011, 6, 166-169.

63 Y. Yang, M. A. Goetzfried, K. Hidaka, M. You, W. Tan, H. Sugiyama and M. Endo, Nano Lett., 2015, 15, 6672-6676.

64 M. Teichmann, E. Kopperger and F. C. Simmel, ACS Nano, 2014, 8, 8487.

65 C. Jung, P. B. Allen and A. D. Ellington, Nat. Nanotechnol., 2016, 11, 157-163.

66 X. Qu, D. Zhu, G. Yao, S. Su, J. Chao, H. Liu, X. Zuo, L. Wang, J. Shi, L. Wang, W. Huang, H. Pei and C. Fan, Angew. Chem., Int. Ed., 2017, 56, 1855-1858.

67 T. Omabegho, R. Sha and N. C. Seeman, Science, 2009, 324, 67-71.

68 R. Masoud, R. Tsukanov, T. E. Tomov, N. Plavner, M. Liber and E. Nir, ACS Nano, 2012, 6, 6272. 
69 M. Liber, T. E. Tomov, R. Tsukanov, Y. Berger and E. Nir, Small, 2015, 11, 568-575.

70 C. Wang, Y. Tao, G. Song, J. Ren and X. Qu, Langmuir, 2012, 28, 14829-14837.

71 Z. G. Wang, J. Elbaz and I. Willner, Nano Lett., 2011, 11, 304-309.

72 H. Gu, J. Chao, S. J. Xiao and N. C. Seeman, Nature, 2010, 465, 202-205.

73 K. Lund, A. J. Manzo, N. Dabby, N. Michelotti, A. JohnsonBuck, J. Nangreave, S. Taylor, R. Pei, M. N. Stojanovic, N. G. Walter, E. Winfree and H. Yan, Nature, 2010, 465, 206-210.

74 K. Yehl, A. Mugler, S. Vivek, Y. Liu, Y. Zhang, M. Fan, E. R. Weeks and K. Salaita, Nat. Nanotechnol., 2016, 11, 184-190.

75 C. Zhou, X. Duan and N. Liu, Nat. Commun., 2015, 6, 8102.

76 M. J. Urban, C. Zhou, X. Duan and N. Liu, Nano Lett., 2015, 15, 8392-8396.

77 X. Yang, Y. Tang, S. D. Mason, J. Chen and F. Li, ACS Nano, 2016, 10, 2324-2330.

78 E. Kopperger, T. Pirzer and F. C. Simmel, Nano Lett., 2015, 15, 2693-2699.

79 A. Krissanaprasit, M. Madsen, J. B. Knudsen, D. Gudnason, W. Surareungchai, V. Birkedal and K. V. Gothelf, ACS Nano, 2016, 10, 2243-2250.

80 Y. Zhang, L. Wang, F. Luo, B. Qiu, L. Guo, Z. Weng, Z. Lin and G. Chen, Chem. Commun., 2017, 53, 2910-2913.

81 L. Peng, P. Zhang, Y. Chai and R. Yuan, Anal. Chem., 2017, 89, 5036-5042.

82 H. Cho, D. Alcantara, H. Yuan, R. A. Sheth, H. H. Chen, P. Huang, S. B. Andersson, D. E. Sosnovik, U. Mahmood and L. Josephson, ACS Nano, 2013, 7, 2032-2041.

83 Y. Peng, R. J. Turberfield, S. Sahu and J. H. Reif, Design of an autonomous DNA nanomechanical device capable of universal computation and universal translational motion, Springer, Berlin, Heidelberg, 2004.

84 F. Dannenberg, M. Kwiatkowska, C. Thachuk and A. J. Turberfield, Nat. Comput., 2014, 14, 195-211.

85 F. Pu, Z. Liu, X. Yang, J. Ren and X. Qu, Chem. Commun., 2011, 47, 6024-6026.

86 J. W. Keum and H. Bermudez, Chem. Commun., 2009, 45, 7036-7038.

87 Z. Xia, P. Wang, X. Liu, T. Liu, Y. Yan, J. Yan, J. Zhong, G. Sun and D. He, Biochemistry, 2016, 55, 1326-1331.

88 V. J. Schüller, S. Heidegger, N. Sandholzer, P. C. Nickels, N. A. Suhartha, S. Endres, C. Bourquin and T. Liedl, ACS Nano, 2011, 5, 9696.

89 M. N. Stojanovic, P. de Prada and D. W. Landry, Nucleic Acids Res., 2000, 28, 2915-2918.

90 M. N. Stojanovic, P. de Prada and D. W. Landry, ChemBioChem, 2001, 2, 411-415.

91 M. N. Stojanovic, T. E. Mitchell and D. Stefanovic, J. Am. Chem. Soc., 2002, 124, 3555-3561.

92 R. Yashin, S. Rudchenko and M. N. Stojanovic, J. Am. Chem. Soc., 2007, 129, 15581.
93 D. Li, W. Cheng, Y. Li, Y. Xu, X. Li, Y. Yin, H. Ju and S. Ding, Anal. Chem., 2016, 88, 7500-7506.

94 X. Liu, A. Niazov-Elkan, F. Wang and I. Willner, Nano Lett., 2013, 13, 219-225.

95 E. S. Andersen, M. Dong, M. M. Nielsen, K. Jahn, R. Subramani, W. Mamdouh, M. M. Golas, B. Sander, H. Stark, C. L. Oliveira, J. S. Pedersen, V. Birkedal, F. Besenbacher, K. V. Gothelf and J. Kjems, Nature, 2009, 459, 73-76.

96 S. M. Douglas, I. Bachelet and G. M. Church, Science, 2012, 335, 831-834.

97 H. Peng, X. F. Li, H. Zhang and X. C. Le, Nat. Commun., 2017, 8, 14378.

98 Y. Chen, M. Wang and C. Mao, Angew. Chem., Int. Ed., 2004, 43, 3554-3557.

99 B. Yurke, A. J. Turberfield, A. P. Mills, F. C. Simmel and J. L. Neumann, Nature, 2000, 406, 605-608.

100 M. Liu, J. Fu, C. Hejesen, Y. Yang, N. W. Woodbury, K. Gothelf, Y. Liu and H. Yan, Nat. Commun., 2013, 4, 2127.

101 J. Elbaz, M. Moshe and I. Willner, Angew. Chem., Int. Ed., 2009, 48, 3834-3837.

102 X. Liu, C. H. Lu and I. Willner, Acc. Chem. Res., 2014, 47, 1673-1680.

103 G. Song, M. Chen, C. Chen, C. Wang, D. Hu, J. Ren and X. Qu, Biochimie, 2010, 92, 121-127.

104 F. Wang, B. Willner and I. Willner, Top. Curr. Chem., 2014, 354, 279-338.

105 M. K. Beissenhirtz and I. Willner, Org. Biomol. Chem., 2006, 4, 3392-3401.

106 J. Elbaz, Angew. Chem., Int. Ed., 2012, 51, 2349-2353.

107 D. Ackermann, T. L. Schmidt, J. S. Hannam, C. S. Purohit, A. Heckel and M. Famulok, Nat. Nanotechnol., 2010, 5, 436.

108 J. Weigandt, C. L. Chung, S. S. Jester and M. Famulok, Angew. Chem., Int. Ed., 2016, 55, 5512-5516.

109 C. Teller and I. Willner, Curr. Opin. Biotechnol., 2010, 21, 376-391.

110 Y. Tian and C. Mao, J. Am. Chem. Soc., 2004, 126, 1141011411.

111 Z. G. Wang, J. Elbaz and I. Willner, Angew. Chem., 2012, 51, 4322.

112 R. Chhabra, J. Sharma, Y. Liu and H. Yan, Nano Lett., 2006, 6, 978-983.

113 T. G. Cha, J. Pan, H. Chen, J. Salgado, X. Li, C. Mao and J. H. Choi, Nat. Nanotechnol., 2014, 9, 39-43.

114 M. von Delius, E. M. Geertsema and D. A. Leigh, Nat. Chem., 2010, 2, 96-101.

115 T. G. Cha, J. Pan, H. Chen, H. N. Robinson, X. Li, C. Mao and J. H. Choi, J. Am. Chem. Soc., 2015, 137, 9429-9437.

116 T. E. Tomov, R. Tsukanov, Y. Glick, Y. Berger, M. Liber, D. Avrahami, D. Gerber and E. Nir, ACS Nano, 2017, 11, 4002-4008.

117 T. E. Tomov, R. Tsukanov, M. Liber, R. Masoud, N. Plavner and E. Nir, J. Am. Chem. Soc., 2013, 135, 11935-11941.

118 R. Tsukanov, T. E. Tomov, M. Liber, Y. Berger and E. Nir, Acc. Chem. Res., 2014, 47, 1789-1798.

119 Y. He and D. R. Liu, Nat. Nanotechnol., 2010, 5, 778-782. 